\title{
1 Effects of large macropores on soil evaporation in salt marshes
}

3 Tingzhang Zhou ${ }^{1,2}$, Pei Xin ${ }^{1, \#}$, Ling Li ${ }^{3}$, D. A. Barry ${ }^{4}$, Jirka Šimůnek ${ }^{2}$

4

$5 \quad{ }^{1}$ State Key Laboratory of Hydrology-Water Resources and Hydraulic Engineering, Hohai

6 University, Nanjing, China

$7 \quad{ }^{2}$ Department of Environmental Sciences, University of California Riverside, Riverside, USA

$8 \quad{ }^{3}$ School of Engineering, Westlake University, Hangzhou, China

$9{ }^{4}$ Laboratoire de technologie écologique (ECOL), Institut d'ingénierie de l'environnement

10 (IIE), Faculté de l'environnement naturel, architectural et construit (ENAC), Ecole

11 Polytechnique Fédérale de Lausanne (EPFL), Lausanne, Switzerland

$13{ }^{\#}$ Corresponding author: Pei Xin, State Key Laboratory of Hydrology-Water Resources and 14 Hydraulic Engineering, Hohai University, Nanjing, China (pei.xin@outlook.com) 


\section{$17 \quad$ Highlights}

18

19 the soil with a low saturated hydraulic conductivity (and thus a low water transport capacity),

34 the macropore behaved as a preferential flow path for groundwater to recharge the surrounding soil during evaporation. The evaporated water originated largely from the macropore rather than the soil matrix, maintaining a high evaporation rate in comparison with

- Laboratory experiments and numerical simulations were conducted to study the effects of macropores on soil evaporation

- Macropores increased evaporation for low-permeability soil with a shallow watertable

- Macropores altered soil saturation conditions

- Vertical water fluxes due to evaporation went through macropores and bypassed the soil matrix

\section{Abstract}

The occurrence of macropores in salt marsh sediments is a natural and ubiquitous phenomenon. Although they are widely assumed to affect pore-water flow in salt marshes significantly, the mechanisms involved and their extent are not well understood. We conducted laboratory experiments and numerical simulations to examine the effect of macropores on soil evaporation. Soil columns packed with either sand or clay and with or without macropores were set up with watertables in the columns set at different levels. A high potential evaporation rate was induced by infrared light and a fan. The results showed that in a homogeneous soil. This effect was more pronounced for sediments with lower hydraulic 
conductivities and shallower watertables. These results improve our understanding of water flow and evaporation in salt marshes with continuous macropores between the soil surface and groundwater.

Keywords: salt marsh, soil evaporation, macropores, preferential flow, HYDRUS

\section{Introduction}

Salt marshes, a type of wetland with herbaceous vegetation (Fig. 1a), are found globally along shorelines (Pendleton et al., 2012). As one of the most productive ecosystems, salt marshes maintain coastal biodiversity and serve as essential habitats for many species of intertidal fauna and flora (Adams, 1963; Moffett et al., 2012; Morris, 1995; Wiegert and

49 Freeman, 1990). They also play essential roles in shoreline protection, fishery support, water quality improvement and carbon sequestration (Pendleton et al., 2012). However, almost half

51 of global salt marshes were lost in the last century (Kennish, 2001), mainly due to land reclamation and sea-level rise (Fagherazzi et al., 2012; Woodworth, 2010). Furthermore, existing marshes are threatened by severe degradation (Balke et al., 2016). Therefore,

54 understanding the behavior of salt marshes subjected to various forcing factors is vital for protecting coastal eco-environments. provide pathways for water, solute and energy transport (Wilson and Gardner, 2006; Xin et al., 2011). The amounts of water and solute (e.g., salt) in a creek-marsh system are affected 
by tides, evapotranspiration (including evaporation and plant root uptake) and rainfall

60 (Moffett et al., 2012; Morris, 1995; Xin et al., 2011 and 2017) (Fig. 1a). Water exchange

61 among surface water, groundwater, and the atmosphere affect soil conditions (e.g., soil aeration) and solute transport (e.g., salt accumulation) in salt marshes (Xin et al., 2017).

Understanding this exchange is crucial to answering two important scientific questions related to marsh ecology: plant zonation (i.e., plant distribution in an organized fashion with distinct spatial patterns) and nutrient outwelling (i.e., marshes export nutrients to coastal water) (Chapman, 1960; Teal, 1962). Recently, intensive studies were conducted to examine surface water and groundwater interactions in creek-marsh systems subjected to tides (Adams, 1963; Cao et al., 2012; Moffett et al., 2012; Shen et al., 2018; Ursino et al., 2004; Wilson and Gardner, 2006; Xiao et al., 2017; Xin et al., 2013). They demonstrated a near-creek pore-water circulation, in which water infiltrates from the marsh platform during flood tides and seeps out of the creek bank and bottom during ebb tides (Cao et al., 2012; Wilson and Gardner, 2006; Xin et al., 2011). This circulation affects solute exchange between the marsh and adjacent sea and regulates soil conditions that determine plant growth and marsh functions (Adams, 1963; Colmer and Flowers, 2008; Dacey and Howes, 1984; Marani et al., 2006; Mendelssohn et al., 1981; Wilson et al., 2015; Xin et al., 2013). By contrast, the effects of evapotranspiration on salt marshes are rarely studied and poorly understood (Xin et al., 2017). Evapotranspiration is a vital component of the global hydrologic cycle and affects the water balance in various hydrological systems (Brutsaert.W., 
1982). Almost $60 \%$ of the terrestrial precipitation returns to the atmosphere through

81 evapotranspiration (Oki and Kanae, 2006). Around 25\% of the total solar radiation on earth is consumed by evapotranspiration (Or et al., 2013; Trenberth et al., 2009). In salt marshes, evapotranspiration affects pore-water flow and solute transport (Xin et al., 2017). For example, evapotranspiration takes freshwater away but leaves salt behind, resulting in salt accumulation in the shallow soil layer and plant rhizosphere that may inhibit plant growth (Adams, 1963; Morris, 1995; Shen et al., 2018). As evapotranspiration desaturates the soil pores during the marsh emergence, it could increase the water infiltration during the tidal overtopping, resulting in enhanced water and solute exchange between marsh sediment and surface water (Shen et al., 2018).

While understanding of soil evaporation at various scales and in different hydrological systems is well established, previous studies predominately focused on homogeneous soils (Brutsaert.W., 1982; Haghighi et al., 2013; Or et al., 2013; Penman, 1948). The effects of soil heterogeneity on evaporation are still poorly understood. Heterogeneity can cause major

94 differences in the duration of evaporation stages and total evaporation flux. Lehmann and Or 95 (2009) examined evaporation in heterogeneous soil consisting of coarse and fine sands and 96 found that capillarity drives the liquid from the coarse domain to the fine one and supplies 97 evaporation from fine sand. This prolongs the period of the high evaporation stage, which 98 may increase the total evaporative flux. Assouline and Narkis (2017) found that different 99 irregular soil configurations could cause a shift in the development of the evaporation front 100 and the duration of different evaporation stages. 

the sediment-water-atmosphere interface and thus affect water flow in salt marshes. Xin et al.

107 (2009) and Xiao et al. (2019) found that macropores behave as preferential pathways and increase the volume of tidally-driven water exchange between marsh soil and tidal creek.

Macropores can also improve soil aeration and enhance salt transport in salt marshes, which may favor plant growth (Colmer and Flowers, 2008; Marani et al., 2006; Mendelssohn et al., 111 1981).

This study is motivated by a field study on a salt marsh in the Yancheng coast $\left(32^{\circ} 43^{\prime}\right.$ -

$113 \quad 34^{\circ} 28^{\prime} \mathrm{N}, 119^{\circ} 48^{\prime}-121^{\circ} 15^{\prime} \mathrm{E}$ ), Jiangsu Province, China. As the typical marsh soil

114 stratigraphy (Carol et al., 2011; Dolphin et al., 1995; Gardner and Porter, 2001; Harvey et al.,

115 1987; Hughes et al., 1998; Perillo et al., 2005; Xin et al., 2009), this site's marsh sediment

116 consists of a low-permeability clay layer overlying a high-permeability sandy-loam layer. The

117 lower sandy-loam layer is relatively well-connected to the creek nearby, and the watertable is

118 controlled by the creek water level. Through the highly-conducted sandy loam layer, the

119 position of the water level in the creek is transferred to the bottom of the clay layer. In this

120 study, we focus only on the surface clay layer and assume that macropores are continuous

121 openings connecting the soil surface with the groundwater from the lower layer. We further 
122 assume that evaporation directly from macropores can be neglected and that macropores

123 enhance evaporation across the soil surface by facilitating underground flow towards the

124 surface soil (Fig. 1c).

125 Based on these assumptions, we conducted laboratory experiments and numerical

126 simulations (in which the vapor flux from the macropore is neglected) on soil evaporation

127 with and without macropores. To expand the results beyond laboratory conditions, a

128 sensitivity analysis with different potential evaporation rates $(1,2$, and $3 \mathrm{~cm} / \mathrm{d})$ and soil

129 textures (clay, silt loam, and sandy loam) was conducted. The results address the following

130 questions: (1) How do macropores affect soil evaporation rate, water flow, and soil saturation

131 distribution; (2) How are these effects altered by potential evaporation, and (3) How is the

132 soil evaporation affected by macropores in combination with soil properties (hydraulic

133 conductivity and soil water retention curve).

134

135 2. Methodology

136 2.1. Laboratory Experiment

137 Experiments were conducted in two cylindrical soil columns with a height of $75 \mathrm{~cm}$ and

138 an inner diameter of $30 \mathrm{~cm}$. The first column was packed with soil without a macropore. In

139 the second column, a tube of the same length of the column was inserted in the center of the

140 column to act as a macropore (Fig. 1c, d). The tube used in this experiment was made from a

141 metal frame (diameter $4 \mathrm{~cm}$ ) covered with a stainless mesh (aperture of around $0.1 \mathrm{~mm}$ ). At

142 the bottom of the columns, permeable porous stones were placed, and the columns were 
143 linked to Marriott bottles, which can provide fixed watertables. Both soil columns and

144 Marriott bottles were placed on high-resolution, self-logging scales so that the soil

145 evaporation rates could be determined by weight changes.

146 Eight sets of experiments with different watertables in the soil column were conducted.

147 The watertables were located between 0 and $70 \mathrm{~cm}$ (in a 10-cm interval) below the soil

148 surface. Before each experiment, the top in the Marriott bottles was adjusted, and the bottles

149 were connected with soil columns. At the beginning of each set of experiments, we adjusted

150 the watertables in the Marriott bottle and left the columns to evaporate. Evaporation was

151 considered to reach a steady-state when the weight of the soil column became steady. The

152 columns were then left to evaporate for around additional $10 \mathrm{~h}$ and the evaporation rates were

153 calculated as the averaged weight loss of the Marriott bottles.

154 All the experiments were conducted under well-controlled indoor conditions. An air

155 conditioner was used to maintain a stable temperature and humidity. To shorten the period

156 needed to reach steady-state conditions, we set a high potential evaporation rate. The room

157 temperature and humidity were set to $30^{\circ} \mathrm{C}$ and $40 \%$, respectively. For each experimental

158 column, an identical fan was used to generate a steady airflow (around $3.8 \mathrm{~m} / \mathrm{s}$ ), with a

159 channel installed on the top of each column to keep airflow uniform. Above the soil columns,

160 infrared lamps ( $250 \mathrm{~W}$, Philips) were installed for supplying heat to the soil surface.

161 Temperature and relative humidity close to the soil surface and $12 \mathrm{~cm}$ above the soil surface

162 were monitored by relative humidity sensors (VP-4, Decagon), which were connected to data

163 loggers. These measured atmospheric conditions were used for calculating the potential 
164 evaporation rate (details in Supplementary Materials). Dielectric soil moisture sensors (5TM,

165 Decagon) were installed at $10,25,40$, and $55 \mathrm{~cm}$ below the soil surface to measure the liquid

166 water saturation. The moisture sensors were installed from outside of the soil column, with

167 their tips $5 \mathrm{~cm}$ away from the column center.

168

\subsection{Numerical Model}

170

To generalize the results from the experiments and obtain further insights into water

171 flow and soil water saturation distributions, we also conducted numerical simulations using

172 HYDRUS (2D/3D) (Šimůnek et al., 2011; Šimůnek et al., 2016). All simulations continued

173 until steady conditions were reached (defined as when the evaporation rate became constant).

174 The soil hydraulic parameters of all materials used in this study are listed in Table 1 . The soil

175 water retention curves were measured in the laboratory and then fitted using the van

176 Genuchten (1980) model (Supplementary Materials and Fig. S2).

177 In this study, the 2D axisymmetric soil domains were discretized using unstructured

178 triangular finite element meshes in an axisymmetric coordinate system (Fig. S3). Although

179 flow in columns without a macropore is expected to be one-dimensional, in order to compare

180 the results from the columns with and without a macropore, we used the same 2D model and

181 the same radially-symmetric coordinate system to simulate flow in the both columns. In all

182 simulations, the wall side boundary was set to no flow. The pressure head was specified at the

183 bottom of the soil column to represent the watertable. For the cases with a macropore, the

184 part of the macropore below the watertable was treated as a fixed-head boundary and the part 
186 quite small in comparison with the soil surface, the evaporation loss from the macropore was

187 neglected in the model.

188 At the soil surface, an atmospheric boundary condition was used to simulate evaporation

189 from the soil. It is well known that actual soil evaporation is determined by the atmospheric

190 condition as well as the soil moisture condition in the surface soil layer (Brutsaert.W., 1982;

191 Camillo, 1986; van de Griend and Owe, 1994). The former is also termed as potential

192 evaporation and was calculated using a widely used evaporation model based on the

193 measured vapor pressure difference and an aerodynamic resistance during the experiments

194 under steady-state conditions (Figs. S5 and S6) assuming thermodynamic equilibrium

195 between the liquid and gaseous phases (detailed calculations in Supplementary Materials).

196 With potential evaporation $\left(E T_{0}\right)$ determined, soil evaporation (i.e., actual evaporation, $E P$ )

197 was calculated in HYDRUS by limiting the evaporative flux using the following two

198 conditions:

$$
E P=-K(h)\left(\frac{\partial h}{\partial z}+1\right) \leq E T_{0}
$$

$$
h_{a} \leq h \leq 0
$$

201 where $K(h)$ is the hydraulic conductivity $\left[\mathrm{LT}^{-1}\right]$ and $h_{a}$ is the limiting pressure head $(\mathrm{cm})$

202 when the first, optimal evaporation stage stops. Note that $h_{a}$ is a function of the equilibrium 


$$
h_{a}=-\frac{R T}{M g} \ln \left(H_{r}\right)
$$

206 where $R$ is the universal gas constant $\left(8.31 \mathrm{~J} \mathrm{~mol}^{-1} \mathrm{~K}^{-1}\right), g$ is the magnitude of

207 gravitational acceleration $\left(9.8 \mathrm{~m} \mathrm{~s}^{-2}\right), M$ is the molecular weight of water $\left(18 \mathrm{~g} \mathrm{~mol}^{-1}\right), T$ is

208 the absolute air temperature $\left({ }^{\circ} \mathrm{K}\right)$, and $H_{r}$ is the relative humidity (set to $40 \%$ as maintained

209 by the air conditioner during the experiments).

210 To shorten the experimental period, we adopted a potential evaporation rate higher than

211 those in natural systems. To generalize the results and get a better insight into real systems, a

212 sensitivity analysis for different potential evaporation rates, i.e., 1, 2, and $3 \mathrm{~cm} / \mathrm{d}$ (Marani et

213 al., 2006), and different soil textures was conducted. Clay, silt loam, and sandy loam, i.e.,

214 three commonly found soil types in salt marshes, were examined in this sensitivity analysis

215 (Table 1 and Fig. S4).

216

\section{3. Results}

\subsection{Results for the sandy columns}

Measured and simulated evaporation rates for the sandy experimental columns with and

without a macropore are shown in Fig. 3. In general, evaporation rates can be divided into three groups depending on the position of watertable:

(1) When watertable depths (distance from the watertable to the soil surface) were 0,10 , and $20 \mathrm{~cm}$ below the soil surface, the evaporation rates in both columns were largely similar and close to the potential evaporation rate (around $6.2 \mathrm{~cm} / \mathrm{d}$ ). The simulation results were consistent with the experimental results. In addition, the presence of the macropore had no 
apparent effect on the evaporation rate.

(2) When watertable depths were 30,40 , and $50 \mathrm{~cm}$ below the soil surface, the evaporation rates decreased below the potential evaporation rate as the watertable decreased, and correspondingly, the soil became less saturated. Differences in evaporation rates between the two cases (with/without a macropore) were minor, and there were no differences in the simulation results.

(3) When watertable depths were 60 and $70 \mathrm{~cm}$ below the soil surface, the evaporation rates were around $1 \mathrm{~cm} / \mathrm{d}$. As the watertable declined to this depth, a dry soil layer with low water saturation was detected during the experiment. Evaporation was expected to occur mainly at low rates via water vapor diffusing through the dry soil layer. Note that vapor diffusion was not considered in the numerical simulations.

The saturation profiles in the sand columns are shown in Fig. 4. The measured results show little differences for different watertable depths between 40 and $60 \mathrm{~cm}$, while the lines representing the simulated results overlap. Due to the uncertainty in the experiments, the

240 porosities of the soil columns were not uniform. While the porosity was assumed to be

241 uniform in the numerical simulations, it was likely not uniform in the laboratory soil column

242 experiments due to packing. This non-uniformity may have resulted in differences between

243 the simulated and measured results. According to the simulation, the macropore did not affect

244 saturation distributions in the sand columns, which was consistent with the evaporation rate

245 results. The soil higher than the watertable remained saturated, and the soil profile became

246 drier when the position was closer to the surface. For different watertable depths, the 
247 saturation at the soil surface decreased as the watertable was lowered until the watertable

248 reached $40 \mathrm{~cm}$, when the surface saturation was almost equal to the residual saturation.

249 Based on the simulation results, we examined the distributions of Darcy flux and soil

250 saturation for different watertable depths (Fig. 5). The evaporation rates and the saturation

251 distributions were similar in both columns. Above the watertable, saturations decreased with

252 increasing elevation, as expected. However, differences in water fluxes between the two

253 columns were apparent. While the Darcy velocities were uniformly vertical both below and

254 above the watertable in cases without a macropore, horizontal flow occurred below the

255 watertable and around the macropore in cases with a macropore. This was more significant

256 around the watertable, where the Darcy flux was the highest. Clearly, the macropore behaved

257 as a preferential flow path for groundwater to recharge the surrounding soil during

258 evaporation, in which case the evaporated water originated from the macropore rather than

259 the soil matrix.

260 We further calculated horizontal fluxes from the macropore to the soil (Fig 6).

261 Consistent with the flow field discussed earlier, the horizontal flux varied with elevation and

262 the position of the watertable. With the watertable at the soil surface, horizontal fluxes started

263 from $0 \mathrm{~cm} / \mathrm{d}$ and increased monotonically as the elevation increased. In contrast, for deeper

264 watertables, the horizontal flux increased first and then decreased around the watertable. For

265 the cases with a macropore, the evaporative flux originates both from water in the macropore

266 (called macropore water) and water flowing upwards from the base of the column through the

267 soil profile. We calculated the ratios between fluxes through the macropore and actual 
evaporation fluxes (Table 2). The ratios were very high (over 90\%) when watertable depths were less than $40 \mathrm{~cm}$. The ratios dropped rapidly for deeper watertables, e.g., from $79.7 \%$ for a 50 -cm depth to $18.1 \%$ for a $70-\mathrm{cm}$ depth, i.e., the effect of the macropore on soil evaporation was more critical for the soil with shallow watertables.

\subsection{Results for the clay columns}

The results for the experiments with clay were more complex than those for sand. The particle size distribution for clay was wider $\left(d_{90} / d_{10}=12.96\right)$, suggesting a wider distribution of pore sizes. Soil heterogeneity might have increased due to the experimental setup, as it was difficult to control the soil packing. Indeed, in order to satisfactorily simulate the measured results for columns with clay soil without a macropore, the saturated hydraulic conductivity was set to $1.0 \mathrm{~cm} / \mathrm{d}$ and the van Genuchten parameters $\alpha$ and $n$ to $0.27 \mathrm{~m}^{-1}$ and 1.93 , respectively (Table 1). However, these values failed to describe the experimental data for clay columns with a macropore, due to uncertainty caused by soil packing (Fig. 7). The numerical model described the experimental data satisfactorily only with manually adjusted parameter values (i.e., the saturated hydraulic conductivity of $1.9 \mathrm{~cm} / \mathrm{d}$ and the van Genuchten parameters $\alpha=0.27 \mathrm{~m}^{-1}$ and $n=2.23$ ).

In the clay columns without a macropore, different watertable depths did not produce different evaporation rates, as in the sand columns. In the clay columns, the evaporation rates 
conductivity of the clay prevented actual evaporation from reaching the potential evaporation

290 even for shallow watertables $(0$ and $20 \mathrm{~cm}$ ). Also, the zero-pressure head line in the soil (i.e.,

291 depth where the pressure head was equal to zero) was significantly lower than the

292 corresponding applied pressure head at the bottom of the column. In contrast, two different

293 evaporation scenarios were observed for the cases with a macropore. Evaporation rates were

294 almost constant and close to the potential evaporation rate when the watertable was close to

295 the soil surface $(0$ and $10 \mathrm{~cm})$. After the watertable dropped to $20 \mathrm{~cm}$, evaporation rates

296 decreased and continued to do so as the watertable was lowered further.

297 Interestingly, actual evaporation for the watertable depth of $70 \mathrm{~cm}$ was $1.7 \mathrm{~cm} / \mathrm{d}$, higher

298 than that for the sand case (when it was less than $1 \mathrm{~cm} / \mathrm{d}$ ). At this level, the watertable was

299 close to the soil column bottom, and thus the impact of the macropore was minor. Instead, it

300 was the large capillary fringe of the clay and higher unsaturated hydraulic conductivity that

301 led to the higher evaporation rate.

302 For the clay columns, the distributions of Darcy fluxes and soil saturations for different

303 watertable levels differed significantly for scenarios without and with a macropore (Fig. 8,

304 note the central section across the macropore is shown). For the former, the one-dimensional

305 behavior is again apparent, similar to the sand cases. The fluxes were uniform and vertical.

306 The soil saturation decreased with increasing elevation in the unsaturated zone. In the near-

307 surface area, neither fluxes nor soil saturations were significantly affected by the watertable

308 depth. However, the two-dimensional behavior occurred around the macropore. Overall, the

309 watertable (defined as the zero-pressure head line) decreased from the macropore to the soil- 
310 wall boundary. Accordingly, the local soil water saturation decreased, as shown in Fig. 8a.

311 When the watertable in the macropore was close to the soil surface, the area far away from

312 the macropore was unsaturated. As the watertable depth increased from 0 to 20,40 , and 60

$313 \mathrm{~cm}$, the flux in the near-soil surface area decreased, which is consistent with the reduced

314 evaporation rates. In this area, the soil saturation was also reduced as the watertable was

315 lowered.

316 Overall trends and variations in the simulated horizontal fluxes through the macropore

317 boundary for the clay columns were similar to those for the sandy columns (compare Fig. 9

318 with Fig. 6). Fluxes similarly decreased with the lower groundwater level and reached their

319 peaks around the watertable. Like the sand cases, the ratio of water flowing from the

320 macropore to the actual evaporation rate was significant (more than 90\%) when the

321 watertable depths were less than $40 \mathrm{~cm}$. It then dropped from around $80 \%$ for a $50-\mathrm{cm}$ depth

322 to $19.9 \%$ for a $70-\mathrm{cm}$ depth. These ratios for the clay cases were slightly higher than those for

323 the sand cases (Table 2).

\subsection{Sensitivity analysis to potential evaporation}

Overall, trends and variations of actual evaporation rates were consistent with

327 experimental evaporation rates for the sand case, i.e., shallow watertables led to high

328 evaporation rates. The effects of a macropore on evaporation rates were more pronounced for

329 soils with a lower hydraulic conductivity, i.e., clay and silt loam. For sandy loam, no apparent

330 differences were caused by a macropore, and evaporation rates for columns with and without 
331

332

333

334

335

336

337

338

339

340

341

342

343

344

345

346

347

a macropore overlapped (Fig. 10).

For silt loam, evaporation rates for columns with a macropore were larger than for columns without a macropore for the same positions of water tables, e.g., for a watertable depth at $40 \mathrm{~cm}$ and $E T_{0}$ of $1 \mathrm{~cm} / \mathrm{d}$ (Fig. 10). The macropore effect increased as the potential evaporation rate increased. For $E T_{0}=3 \mathrm{~cm} / \mathrm{d}$, evaporation rates for columns with a macropore were larger than those for columns without a macropore for watertable depths from 10 to 50 $\mathrm{cm}$. As the potential evaporation rate increased, the macropore played an increasingly important role in affecting the actual evaporation rates for cases with shallow watertables. For both silt loam and sandy loam, actual evaporation rates for scenarios without a macropore reached the potential evaporation rate when the watertable was close to the soil surface, indicating that soils were permeable and able to maintain a high evaporation rate. In contrast, clay, with the lowest hydraulic conductivity among all three soil types, could not support a high evaporation rate without a macropore. This result was demonstrated by the results with shallow watertables. For a watertable close to the soil surface, evaporation rates were similar for scenarios with and without a macropore for $E T_{0}=1 \mathrm{~cm} / \mathrm{d}$. As $E T_{0}$ increased to 2 and $3 \mathrm{~cm} / \mathrm{d}$, scenarios with a macropore still reached the potential evaporation rate, but for those without a macropore, actual evaporation rates decreased to around $1 \mathrm{~cm} / \mathrm{d}$, which was the value of the soil saturated hydraulic conductivity.

Ratios of water fluxes through the macropore to the actual evaporation rate for cases considered in the sensitivity analysis are demonstrated in Fig. 11. Overall trends and values for these cases are similar to the experimental cases, being over $90 \%$ when the watertable 
352 depths are less than $40 \mathrm{~cm}$ and dropping rapidly from $80.7 \%$ for a 50 -cm watertable depth to

353 about $20 \%$ for a $70-\mathrm{cm}$ watertable depth. Different potential evaporation rates and soil

354 properties did not show much influence on the ratios of water fluxes from a macropore to the

355 actual evaporation rate. These results indicate that the watertable depth significantly affects

356 the water bypass caused by the macropore.

357

358

\section{Discussion}

359

While this study focused on water flow in cylindrical soil columns, it should help to

increase our understanding of the effects of macropores on water flow and solute transport in real salt marshes. Macropores did not affect soil evaporation markedly in high-permeability soils such as sandy loam. However, low-permeability silt loams and clays were unable to deliver enough water to the soil surface to maintain a high evaporation rate. Under such conditions, continuous macropores in contact with groundwater behave as preferential flow paths, providing water for evaporation. overlying a high-permeability sandy-loam layer (Cao et al., 2012; Dolphin et al., 1995; Xiao et al., 2017; Xin et al., 2012). Enhanced evaporation would intensify water exchange between creek water and marsh soil. While creek water in natural systems is commonly saline and evaporation would lead to soil salinization (Xin et al., 2017), we used freshwater in this study

371 to minimize this effect. 
373 layers. This is expected to lower soil aeration and oxygen availability in marsh soils, which

374 could affect plant root respiration and thus marsh plant growth (Colmer and Flowers, 2008;

375 Dacey and Howes, 1984; Mendelssohn et al., 1981; Silvestri et al., 2005). However, in

376 macropores, there is no capillary-induced upward flow, which would decrease soil saturation

377 of near-surface soil layers in soils next to macropores with deeper watertables. Under such

378 conditions, evaporation would be reduced, similarly as associated water exchange. Natural

379 marshes are periodically inundated by tidal water. For less saturated soils, tidal infiltration

380 would increase, which would lead to enhanced water exchange in shallow marsh soils.

381 Our results show that the contribution of water from the macropore to the evaporation

382 flux is significant compared with that which comes from the watertable and passes entirely

383 through the soil before evaporation. With denser distributions of macropores, most of the

384 evaporated water would bypasses the soil matrix and has only a little contact with soil grains.

385 This is expected to affect the fate of chemicals transported through marsh soils. For example,

386 chemicals in deep soil layers would be unlikely to be transported to the shallow soil layers

387 due to weak upward flow. Furthermore, interactions between the deep soil layer and creek

388 water would be weakened.

389 Guimond et al. (2019) recently found that the presence of macropores reduces carbon

390 sequestration in salt marshes. This is consistent with Xin et al. (2009) and Xiao et al. (2019)

391 who indicated that macropores likely enhance lateral water exchange between marsh soil and

392 creek water, which may increase a lateral loss of dissolved carbon. These same authors also

393 suggested that macropores would decrease soil water saturation of the shallow soil layer and 
394 thus improve local soil aeration conditions. This would favor carbon oxidation and lead to a

395 further vertical carbon loss. Our results indicate that while macropores enhance evaporation

396 from soil columns with a fixed watertable, the soil water saturation in the upper soil layer is

397 increased. This would lead to reduced oxygen availability and inhibited carbon oxidation. This

398 is inconsistent with previous studies (Xin et al., 2009; Xiao et al., 2019). In natural salt marshes,

399 evaporation would lower a local watertable, which would improve soil aeration of the shallow

400 soil layer. The effects of macropores on carbon sequestration thus depend on how they

401 synergistically regulate lateral water flow, the position of the watertable, and associated

402 aeration conditions.

403 Natural marshes are affected by the combination of evaporation, rainfall and tidal

404 fluctuations. Watertables are dynamic, particularly in near-creek zones (Wilson and Gardner,

405 2006; Xin et al., 2011). Our results indicate that when watertables are at different depths, the

406 effects of macropores on soil evaporation are not consistent. Macropores are expected to

407 speed up soil evaporation in the clay marsh with shallow watertables that often occur after

408 tidal inundation or rainfall events. However, the near-surface soil is hard to desaturate as

409 macropores allow water to be easily transported from the lower soil profile. As roots of marsh

410 plants are distributed in the shallow soil layer, this more rapid evaporation would not reduce

411 the period of oxygen deficiency, which would not favor plant growth.

412

413 5. Conclusions

414 Based on laboratory experiments and numerical simulations, we examined the effects of 
415 large macropores on soil evaporation in soil columns. From the results, the following

416 conclusions can be drawn:

417 (1) The macropore increased evaporation rates in low-permeability soils with shallow

418 watertables. The macropore did not significantly affect soil evaporation in high

419 permeability soils (e.g., sand and sandy loam).

420 (2) The presence of the macropore altered water flow in the soil compared to that

421 without the macropore. The macropore behaved as a preferential flow path,

422 delivering groundwater to the shallow soil, which resulted in higher soil saturation in

423 the near-surface area.

(3) Water flow from the macropore contributed significantly to the actual evaporation rate, and this proportion was reduced as the watertable declined. Vertical flow presence of a macropore.

While the present study has produced insights into steady-state evaporation in salt

429 marshes, it focused on steady-state conditions in idealized soil columns with steady

430 watertables. Further investigations should be conducted to confirm the results from this study

431 in real marshes, in which tides, rainfall, and evaporation would lead to dynamic watertables.

432 Macropores are distributed randomly and vary in diameter and depth. Furthermore, the

433 density and size of macropores likely vary spatially and are related to creek networks.

434 Notwithstanding these differences, the present study highlights the importance of macropores 435 on soil evaporation, and their potential effects on surface water and groundwater interactions 
and solute transport/reaction in salt marshes.

437

438

\section{Acknowledgment}

439

This work was supported by the National Natural Science Foundation of China (51579077).

440

\section{References}

442 Adams, D.A., 1963. Factors influencing vascular plant zonation in North Carolina salt marshes. Ecology, 44(3): 445-456. DOI: 10.2307/1932523

444 Assouline, S., Narkis, K., 2017. Evaporation from soil containers with irregular shapes. Water Resources Research, 53(11): 8795-8806. DOI:10.1002/2017wr021166

Balke, T., Stock, M., Jensen, K., Bouma, T.J., Kleyer, M., 2016. A global analysis of the seaward salt marsh extent: The importance of tidal range. Water Resources Research,

Brutsaert,W., 1982. Evaporation into the Atmosphere: Theory, History, and Applications. 52(5): 3775-3786. DOI:10.1002/2015wr018318

Camillo, P.J., 1986. Resistance parameter for bare-soil evaporation models. Soil Science, 141: Springer Netherlands. DOI: $\underline{10.1007 / 978-94-01 w 7-1497-6}$

Cao, M., Xin, P., Jin, G., Li, L., 2012. A field study on groundwater dynamics in a salt marsh - Chongming Dongtan wetland. Ecological Engineering, 40(Supplement C): 61-69. DOI:10.1016/j.ecoleng.2011.12.018 

DOI:10.1016/j.jhydrol.2011.04.007

Chapman, V.J., 1960. Salt marshes and salt deserts of the world, Ecology of Halophytes. pp. 213-214.

462

Colmer, T.D., Flowers, T.J., 2008. Flooding tolerance in halophytes. New Phytologist, 179(4): 964-974. DOI: 10.1111/j.1469-8137.2008.02483.x

Dacey, J.W.H., Howes, B.L., 1984. Water uptake by roots controls water table movement and sediment oxidation in short spartina marsh. Science, 224(4648): 487-489. DOI:10.1126/science.224.4648.487

De Vries, D.A., 1958. Simultaneous transfer of heat and moisture in porous media. Eos, Transactions American Geophysical Union, 39(5): 909-916. DOI:10.1029/TR039i005p00909

Dolphin, T.J., Hume, T.M., Parnell, K.E., 1995. Oceanographic processes and sediment mixing on a sand flat in an enclosed sea, Manukau Harbour, New Zealand. Marine

Fagherazzi, S. et al., 2012. Numerical models of salt marsh evolution: Ecological, geomorphic, and climatic factors. Reviews of Geophysics, 50(1).

Gardner, L.R., Porter, D.E., 2001. Stratigraphy and geologic history of a southeastern salt marsh basin, North Inlet, South Carolina, USA. Wetlands Ecology and Management, 
479

480

481

482

483

484

485

486

487

488

489

490

491

492

493

494

495

496

497

498

Guimond J.A., Seyfferth A.L., Moffett K.B., Michael H.A. (2019). A physicalbiogeochemical mechanism for negative feedback between marsh crabs and carbon storage. Environmental Research Letters. In press. DOI:10.1088/1748-9326/ab60e2

Haghighi, E., Shahraeeni, E., Lehmann, P., Or, D., 2013. Evaporation rates across a convective air boundary layer are dominated by diffusion. Water Resources Research, 49(3): 1602-1610. DOI:10.1002/wrcr.20166

Harvey, J.W., Germann, P.F., Odum, W.E., 1987. Geomorphological control of subsurface hydrology in the creekbank zone of tidal marshes. Estuarine, Coastal and Shelf Science, 25(6): 677-691. DOI: $\underline{10.1016 / 0272-7714(87) 90015-1}$

Hughes, C.E., Binning, P., Willgoose, G.R., 1998. Characterisation of the hydrology of an estuarine wetland. Journal of Hydrology, 211(1-4): 34-49. DOI:10.1016/s0022-

\section{$\underline{1694(98) 00194-2}$}

Kennish, M.J., 2001. Coastal salt marsh systems in the US: A review of anthropogenic impacts. Journal of Coastal Research, 17(3): 731-748.

Lehmann, P., Or, D., 2009. Evaporation and capillary coupling across vertical textural contrasts in porous media. Physical Review E, 80(4): 046318. DOI: $\underline{10.1103 / \text { PhysRevE.80.046318 }}$

Marani, M. et al., 2006. Spatial organization and ecohydrological interactions in oxygenlimited vegetation ecosystems. Water Resources Research, 42, W06D06 DOI:10.1029/2005wr004582 
499

500

501

502

503

504

505

506

507

508

509

510

511

512

513

514

515

516

517

518

519

Mendelssohn, I.A., McKee, K.L., Patrick, W.H., 1981. Oxygen deficiency in spartina alterniflora roots: Metabolic adaptation to anoxia science, 214(4519): 439-441. DOI: $\underline{10.1126 / \text { science.214.4519.439 }}$

Moffett, K.B., Gorelick, S.M., McLaren, R.G., Sudicky, E.A., 2012. Salt marsh ecohydrological zonation due to heterogeneous vegetation-groundwater-surface water interactions. Water Resources Research, 48, W02516 DOI:10.1029/2011wr010874

Morris, J.T., 1995. The mass balance of salt and water in intertidal sediments: Results from North Inlet, South Carolina. Estuaries, 18(4): 556-567. DOI: $\underline{10.2307 / 1352376}$

Oki, T., Kanae, S., 2006. Global hydrological cycles and world water resources. Science, 313(5790): 1068-1072. DOI: $10.1126 /$ science.1128845

Or, D., Lehmann, P., Shahraeeni, E., Shokri, N., 2013. Advances in soil evaporation physics-A review. Vadose Zone Journal, 12: 1-16 vzj2012.0163. DOI: $10.2136 /$ vzj2012.0163

Pendleton, L. et al., 2012. Estimating global "Blue Carbon" emissions from conversion and degradation of vegetated coastal ecosystems. PLoS One, 7(9): 7. DOI: $10.1371 /$ journal.pone.0043542

Penman, H.L., 1948. Natural evaporation from open water, hare soil and grass. Proceedings of the Royal Society of London. Series A, Mathematical and physical sciences, 193(1032): 120-45. DOI:10.1098/rspa.1948.0037

Perillo, G.M.E., Pérez, D.E., Piccolo, M.C., Palma, E.D., Cuadrado, D.G., 2005. Geomorphologic and physical characteristics of a human impacted estuary: Quequén 

DOI: $\underline{10.1016 / j . e c s s .2004 .09 .018}$

522

Philip, J.R., De Vries, D.A., 1957. Moisture movement in porous materials under temperature gradients. Eos, Transactions American Geophysical Union, 38(2): 222-232. DOI: $10.1029 / \mathrm{TR} 038 \mathrm{i} 002 \mathrm{p} 00222$

Shen, C.J., Zhang, C.M., Xin, P., Kong, J., Li, L., 2018. Salt dynamics in coastal marshes: formation of hypersaline zones. Water Resources Research, 54(5): 3259-3276. DOI:10.1029/2017wr022021

Silvestri, S., Defina, A., Marani, M., 2005. Tidal regime, salinity and salt marsh plant zonation. Estuarine, Coastal and Shelf Science, 62(1-2): 119-130. DOI: $10.1016 /$ j.eess.2004.08.010

Šimůnek, J., M.Th.van Genutchen, M. Šejna, 2011. The HYDRUS Software Package for Simulating Two- and Three-Dimensional Movement of Water, Heat, and Multiple Solutes in Variably-Saturated Porous Media, Technical Manual, Version 2.0. PC Progress, Prague, Czech Republic.

Šimůnek, J., van Genuchten, M.T., Šejna, M., 2016. Recent developments and applications of the HYDRUS computer software packages. Vadose Zone Journal, 15: vzj2016.04.0033 DOI:10.2136/vzj2016.04.0033

Teal, J.M., 1962. Energy flow in the salt marsh ecosystem of Georgia. Ecology, 43(4): 614624. DOI: $\underline{10.2307 / 1933451}$

Trenberth, K.E., Fasullo, J.T., Kiehl, J., 2009. Earth's global energy budget. Bulletin of the 
542 Ursino, N., Silvestri, S., Marani, M., 2004. Subsurface flow and vegetation patterns in tidal DOI:10.1029/2003wr002702

van de Griend, A.A., Owe, M., 1994. Bare soil surface resistance to evaporation by vapor

van Genuchten, M.Th., 1980. A closed-form equation for predicting the hydraulic 898. DOI: $10.2136 /$ sssaj $1980.03615995004400050002 \mathrm{x}$

Wiegert, R.G., Freeman, B.J., 1990. Tidal salt marshes of the southeast Atlantic Coast: A community profile. United States. doi: $\underline{10.2172 / 5032823}$

Wilson, A.M. et al., 2015. Groundwater controls ecological zonation of salt marsh macrophytes. Ecology, 96(3): 840-849. DOI:10.1890/13-2183.1

Wilson, A.M., Gardner, L.R., 2006. Tidally driven groundwater flow and solute exchange in a marsh: Numerical simulations. Water Resources Research, 42, W01405 DOI: $\underline{10.1029 / 2005 w r 004302}$

Woodworth, P.L., 2010. A survey of recent changes in the main components of the ocean tide. Continental Shelf Research, 30(15): 1680-1691. DOI:10.1016/j.csr.2010.07.002

560 Xiao, K. et al., 2017. Tidal groundwater flow and its ecological effects in a brackish marsh at the mouth of a large sub-tropical river. Journal of Hydrology, 555: 198-212. 
563 Xiao, K., Wilson, A.M., Li, H., Ryan, C., 2019. Crab burrows as preferential flow conduits for groundwater flow and transport in salt marshes: A modeling study. Advances in Water Resources, 132: 103408. DOI:10.1016/j.advwatres.2019.103408

Xin, P., Jin, G., Li, L., Barry, D.A., 2009. Effects of crab burrows on pore water flows in salt marshes. Advances in Water Resources, 32(3): 439-449. DOI:10.1016/j.advwatres.2008.12.008

Xin, P., Kong, J., Li, L., Barry, D.A., 2012. Effects of soil stratigraphy on pore-water flow in a creek-marsh system. Journal of Hydrology, 475: 175-187. DOI:10.1016/j.jhydrol.2012.09.047

572 Xin, P., Li, L., Barry, D.A., 2013. Tidal influence on soil conditions in an intertidal creekmarsh system. Water Resources Research, 49. DOI: 10.1029/2012WR012290

574 Xin, P., Yuan, L.-R., Li, L., Barry, D.A., 2011. Tidally driven multiscale pore water flow in a creek-marsh system. Water Resources Research, 47, W07534 DOI: $\underline{10.1029 / 2010 w r 010110}$

577 Xin, P. et al., 2017. Combined effects of tides, evaporation and rainfall on the soil conditions in an intertidal creek-marsh system. Advances in Water Resources, 103(2017): 1-15. 
582 Table 1. Soil hydraulic parameters (van Genuchten, 1980) for soils used in this study. The

583 first two soil types, i.e., Sand and Clay, were used in the laboratory experimental columns,

584 while the last three soil types, i.e., Sandy Loam, Silt Loam, and Clay-S, were used in the

585 sensitivity analysis.

\begin{tabular}{lccccc}
\hline Soil type & Sand & Clay & Sandy loam & Silt loam & Clay-S \\
\hline$K_{S}(\mathrm{~cm} / \mathrm{d})$ & 330.0 & 1.0 & 106.1 & 10.8 & 4.8 \\
Porosity & 0.40 & 0.38 & 0.41 & 0.45 & 0.38 \\
$S_{\text {wres }}$ & 0.15 & 0.18 & 0.16 & 0.15 & 0.18 \\
$\alpha\left(\mathrm{m}^{-1}\right)$ & 5 & 0.27 & 7.5 & 2 & 0.8 \\
$n$ & 1.7 & 1.93 & 1.89 & 1.41 & 1.09 \\
\hline
\end{tabular}

586 
587 Table 2. Ratios (in \%) of the water flux through the macropore to the actual evaporation rate 588 in experimental columns with different watertable depths and soil types.

\begin{tabular}{|c|c|c|c|c|c|c|c|c|}
\hline \multirow{2}{*}{ Soil Type } & \multicolumn{8}{|c|}{ Watertable depth $(\mathrm{cm})$} \\
\hline & 0 & 10 & 20 & 30 & 40 & 50 & 60 & 70 \\
\hline Sand & 99.3 & 98.9 & 98.1 & 95.8 & 90.5 & 79.7 & 53.0 & 18.1 \\
\hline Clay & 99.3 & 99.2 & 98.1 & 96.0 & 90.5 & 80.8 & 59.3 & 20.0 \\
\hline
\end{tabular}



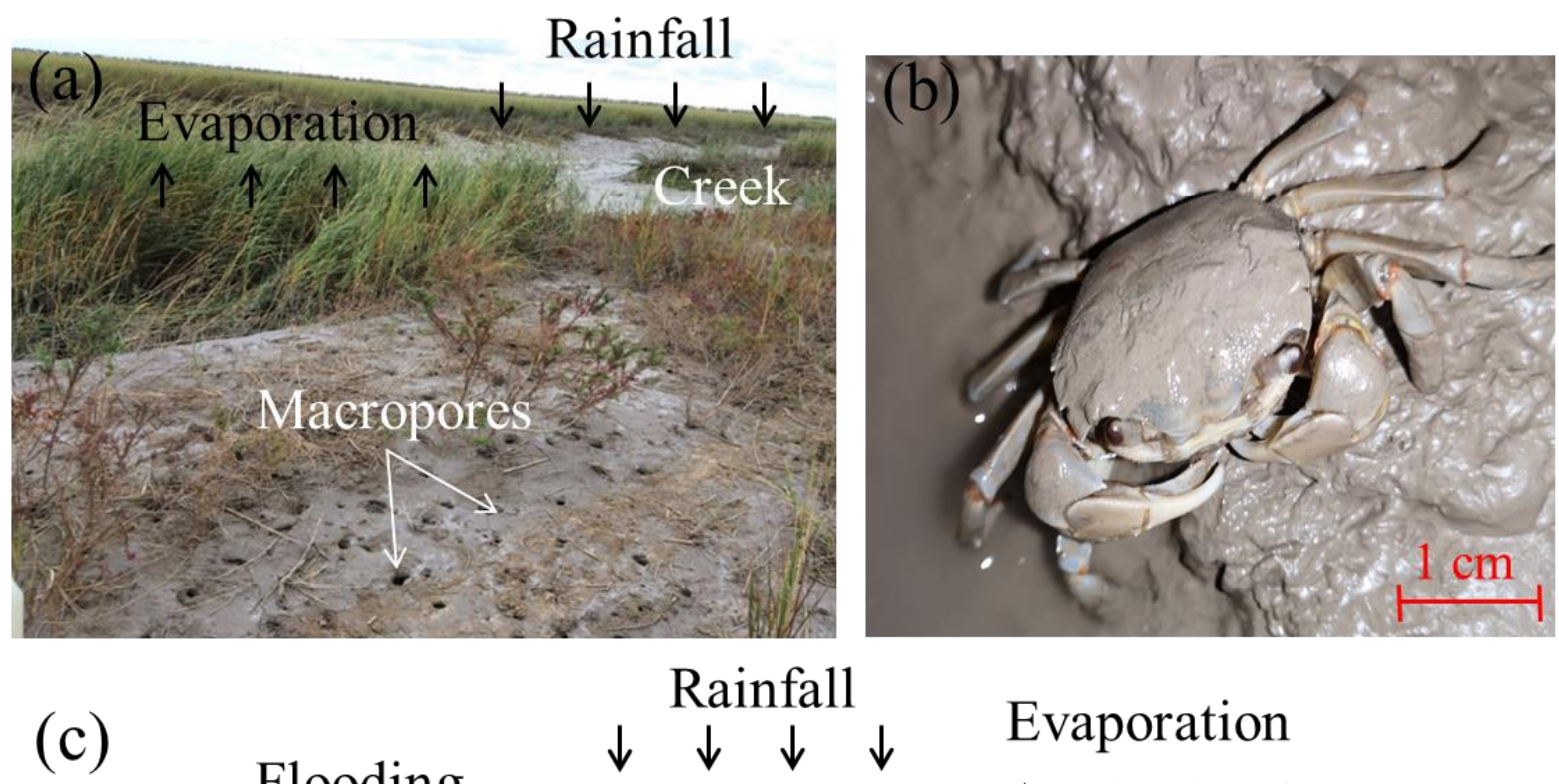

\section{Rainfall}

(c) $\downarrow \downarrow \downarrow \downarrow \downarrow$ Evaporation

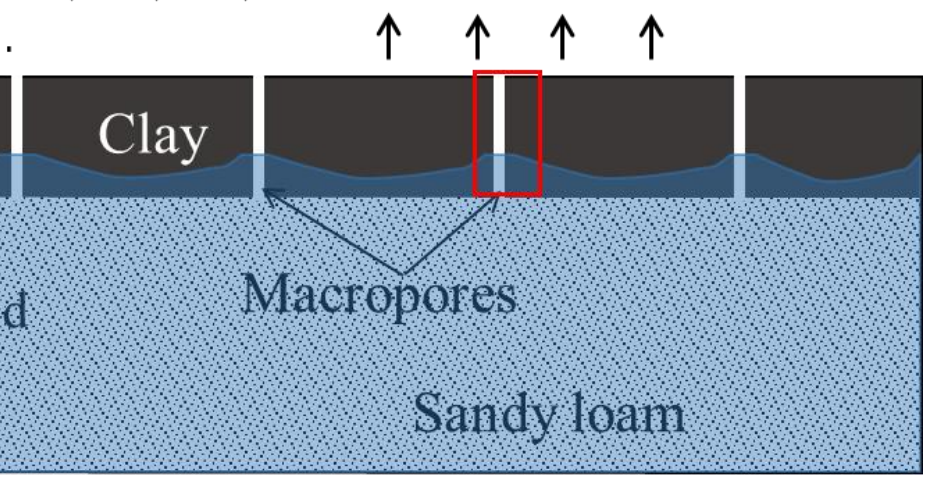

591 Figure 1. (a) A photograph of a creek in Chuandong, Jiangsu, China; (b) a photo of a crab;

592 and (c) a schematic diagram of the creek-marsh system with macropores (a red rectangle

593 indicates the system used in this study). 


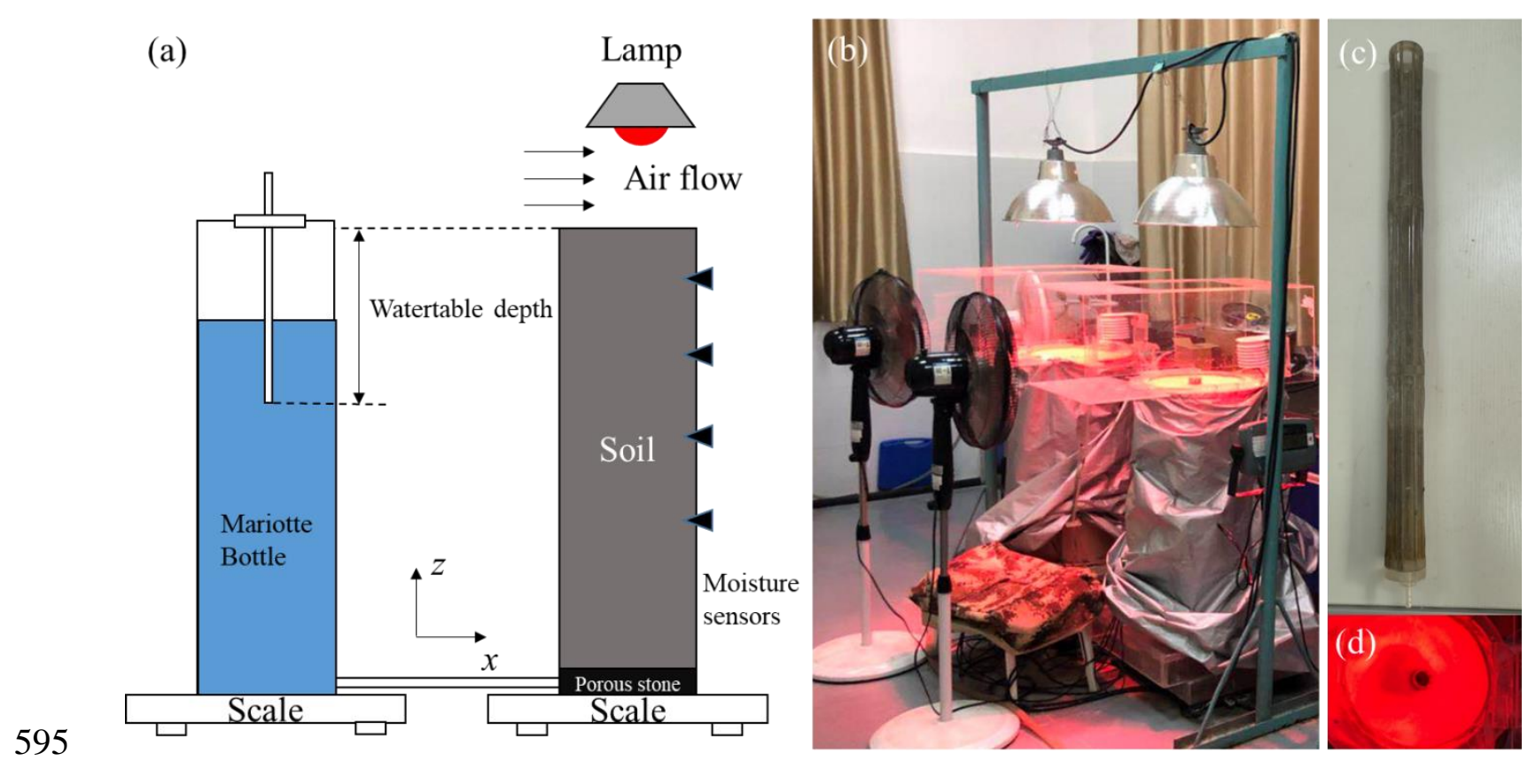

596 Figure 2. (a) A schematic diagram of the experimental setup; (b) a photograph of the

597 experimental setup; (c) the tube used as a macropore in the experiments; (d) a photograph of

598 the top of the column with a macropore illuminated by a lamp. 


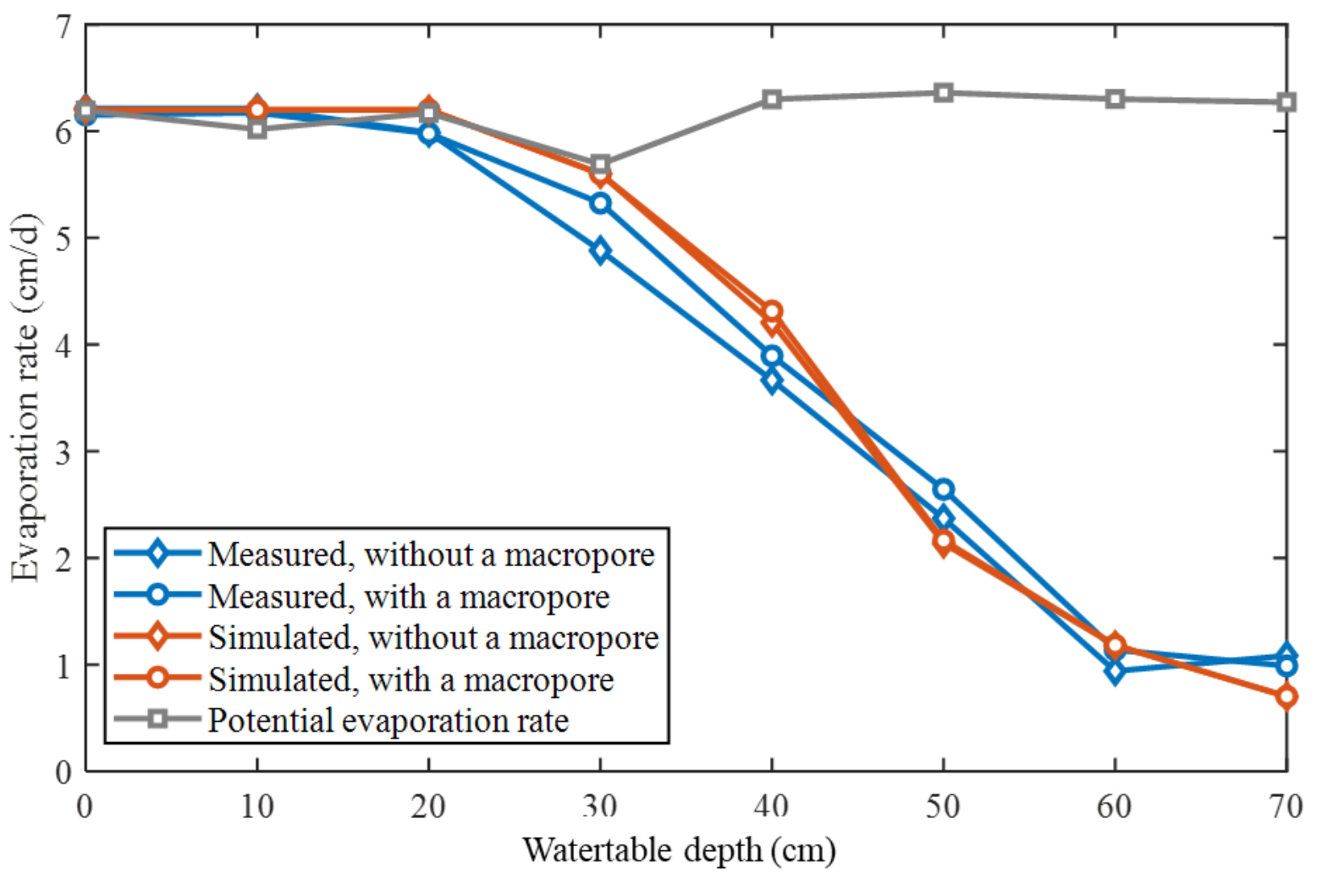

599

600 Figure 3. Measured and simulated (steady state) evaporation rates for the sandy experimental

601 columns with different watertable depths. 
(a) $0 \mathrm{~cm}$

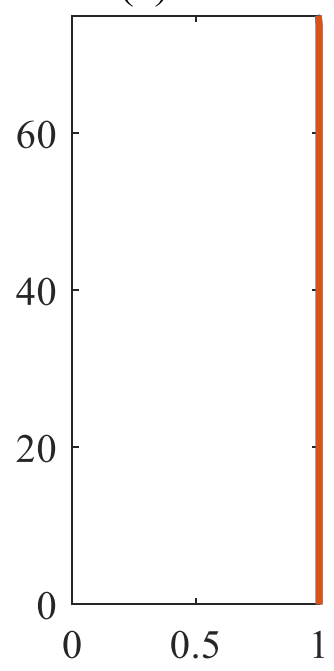

(b) $10 \mathrm{~cm}$

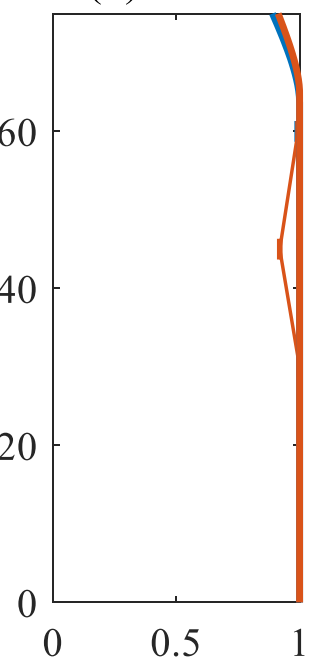

(c) $20 \mathrm{~cm}$

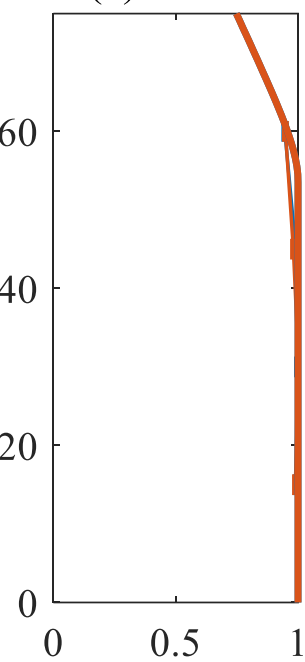

(d) $30 \mathrm{~cm}$

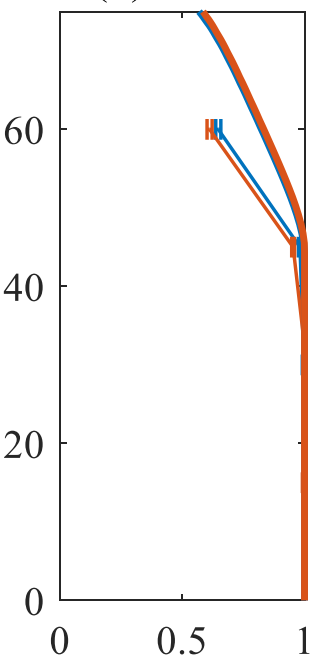

(e) $40 \mathrm{~cm}$

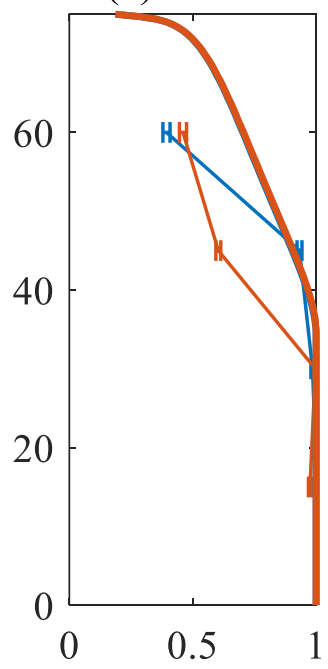

(f) $50 \mathrm{~cm}$

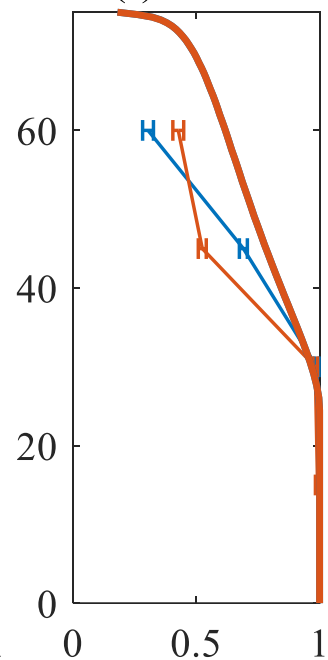

(g) $60 \mathrm{~cm}$

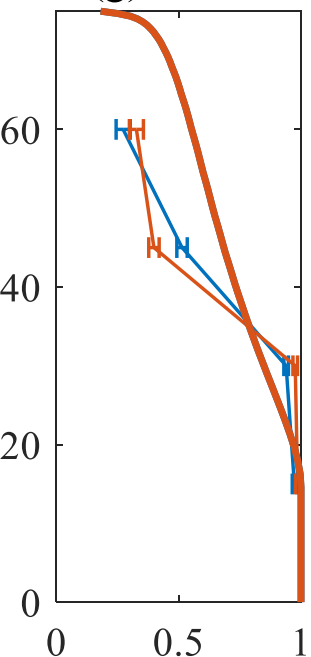

(h) $70 \mathrm{~cm}$

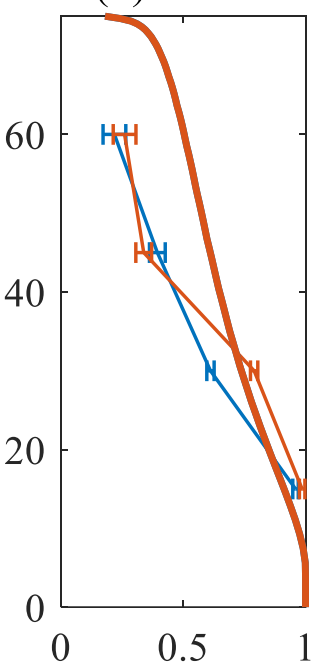

Saturation (-) $\quad$ Saturation (-) $\quad$ Saturation (-) $\quad$ Saturation (-)

f Measured, without macro-pore $f$ Measured, with a macro-pore

- Simulated, without macro-pore $\longrightarrow$ Simulated, with a macro-pore

602

603 Figure 4. Measured and simulated saturations for the sandy experimental columns with

604 different watertable depths: (a) $0 \mathrm{~cm}$, (b) $10 \mathrm{~cm}$, (c) $20 \mathrm{~cm}$, (d) $30 \mathrm{~cm}$, (e) $40 \mathrm{~cm}$, (f) $50 \mathrm{~cm}$,

605 (g) $60 \mathrm{~cm}$, and (h) $70 \mathrm{~cm}$ ). Red lines overlap blue lines. The stand variances of the measured

606 results were given by the horizontal bars. 
(a) Watertable depth $=0 \mathrm{~cm}$

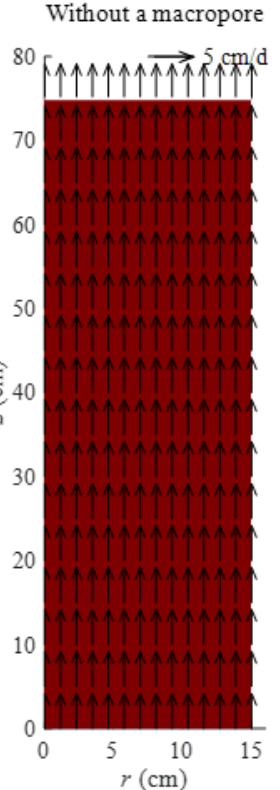

(c) Watertable depth $=40 \mathrm{~cm}$

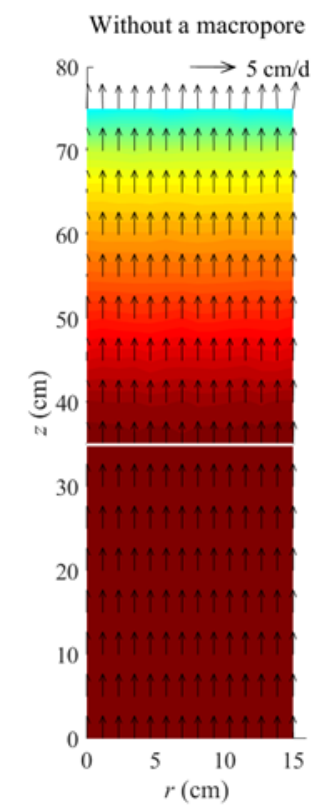

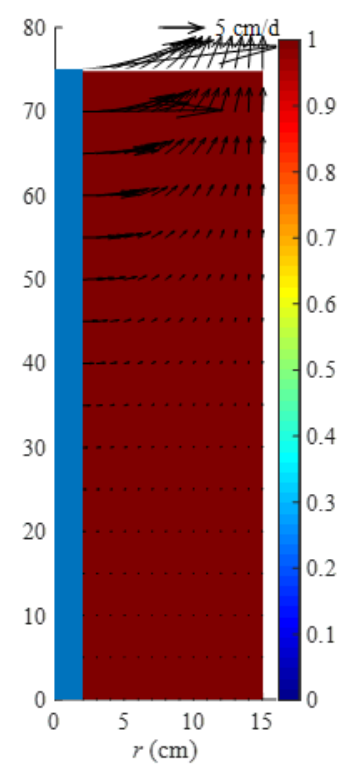

With a macropore

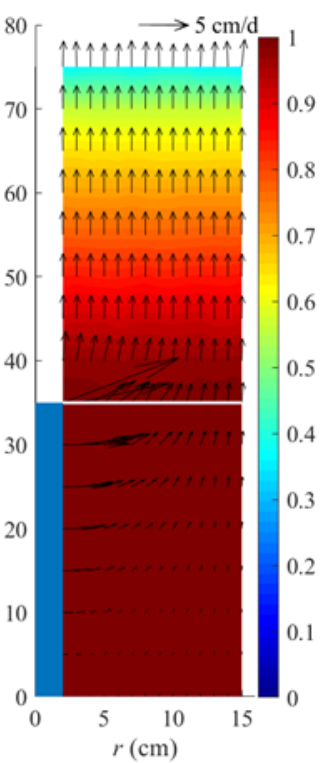

(b) Watertable depth $=20 \mathrm{~cm}$

Without a macropore
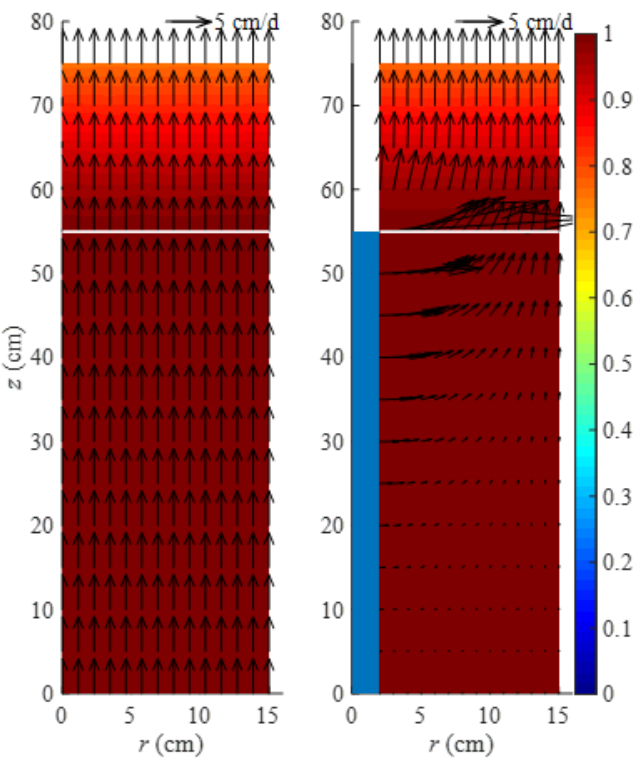

(d) Watertable depth $=60 \mathrm{~cm}$
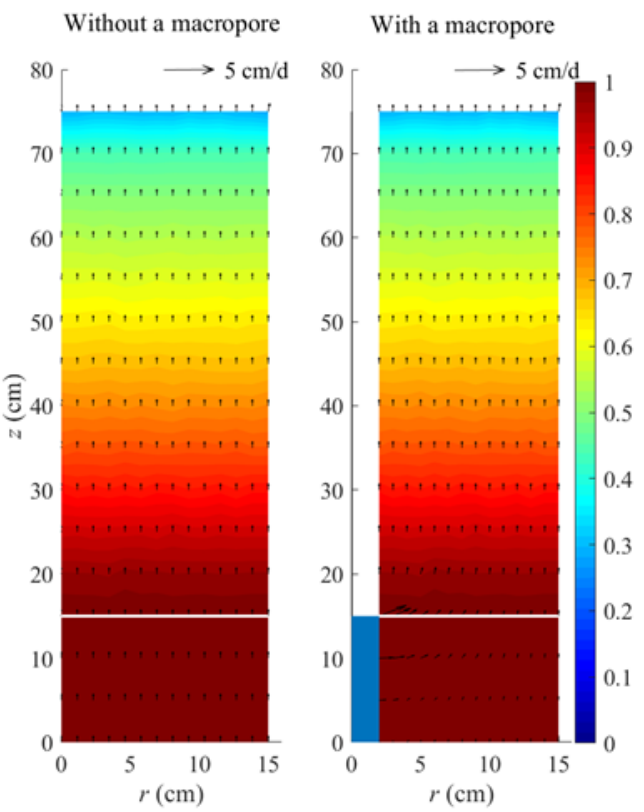

608 Figure 5. Simulation results for the sandy experimental columns without (left) and with

609 (right) a macropore for watertable depths of (a) $0 \mathrm{~cm}$, (b) $20 \mathrm{~cm}$, (c) $40 \mathrm{~cm}$, and (d) $60 \mathrm{~cm}$.

610 Water saturation is shown in color, while the arrows represent the Darcy velocities (the

611 magnitude is indicated by the arrow length). The white lines indicate the position where the

612 hydraulic head is equal to 0. 


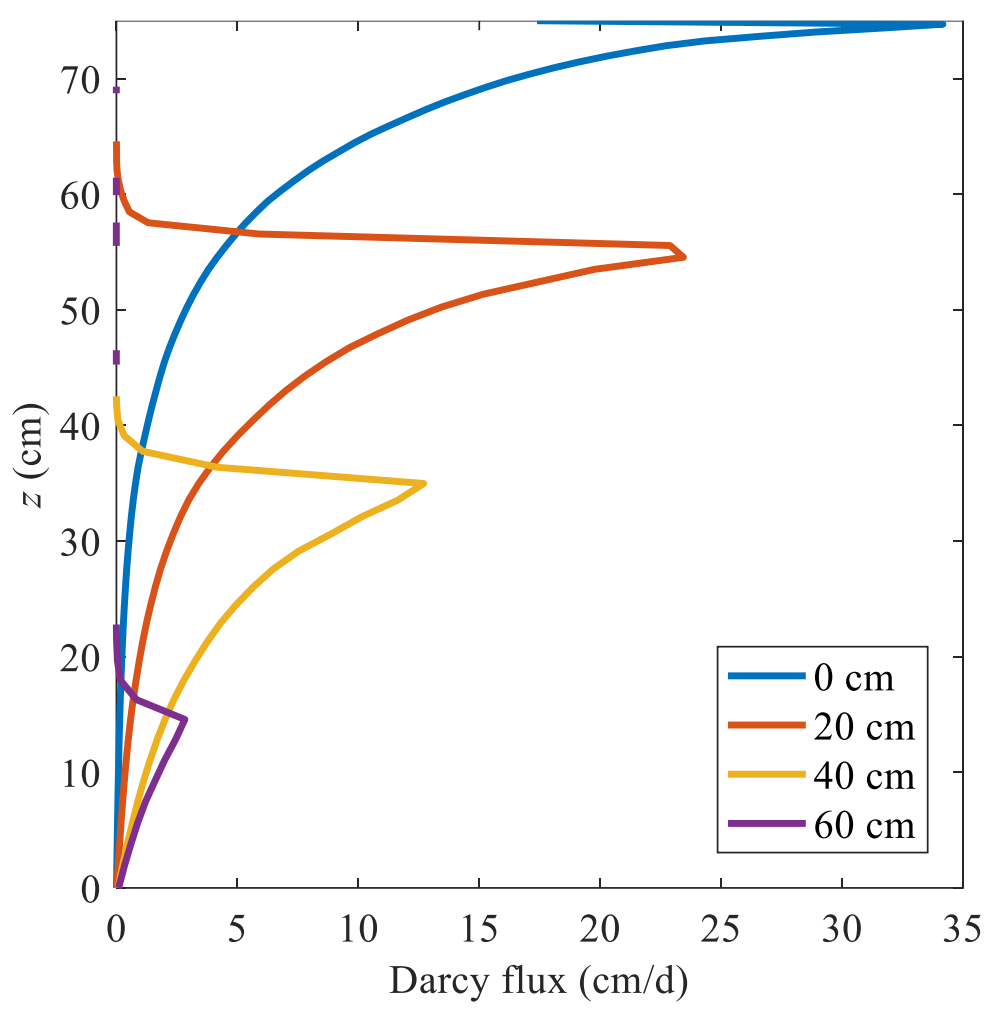

614 Figure 6. Simulated horizontal Darcy fluxes at the macropore boundary of the sandy columns 615 with different watertable depths. 


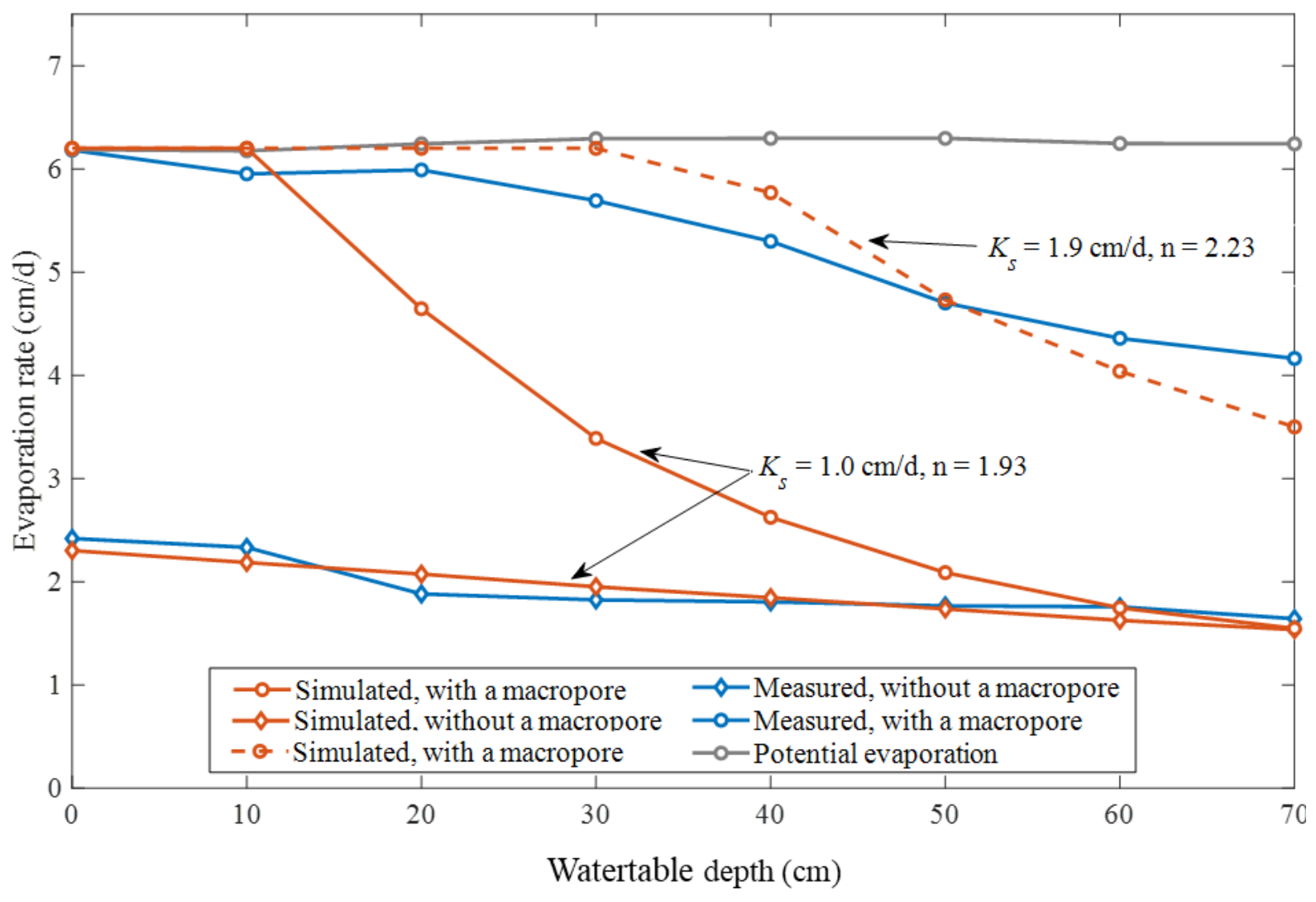

616

617 Figure 7. Measured and simulated steady state evaporation rates for the clay experimental

618 columns with different watertable depths. The solid red lines represent simulation with the

619 same soil properties, with and without a macropore. The dashed red line represents the

620 simulation using the adjusted soil properties $\left(K_{s}=1.9 \mathrm{~cm} / \mathrm{d}, n=2.23\right)$ that fit well the

621 experimental results. 
(a) Watertable depth $=0 \mathrm{~cm}$

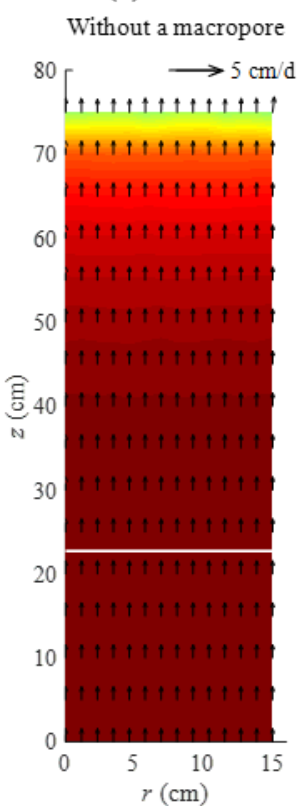

(c) Watertable depth $=40 \mathrm{~cm}$

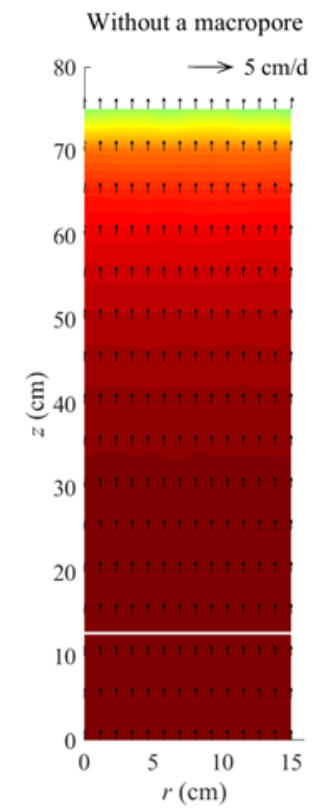

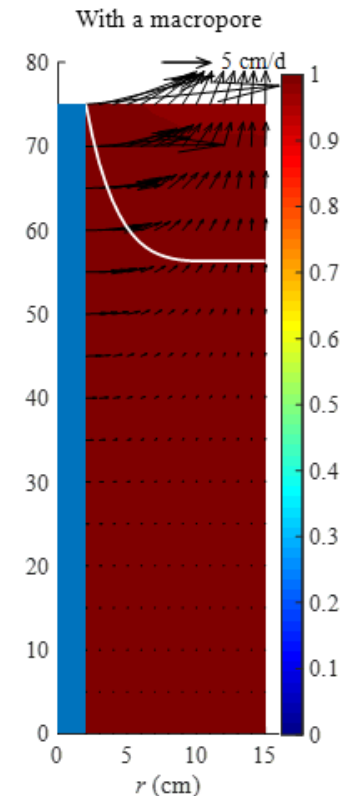

With a macropore

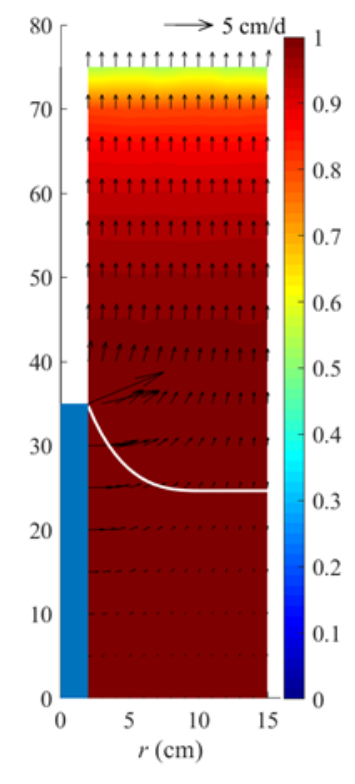

(b) Watertable depth $=20 \mathrm{~cm}$

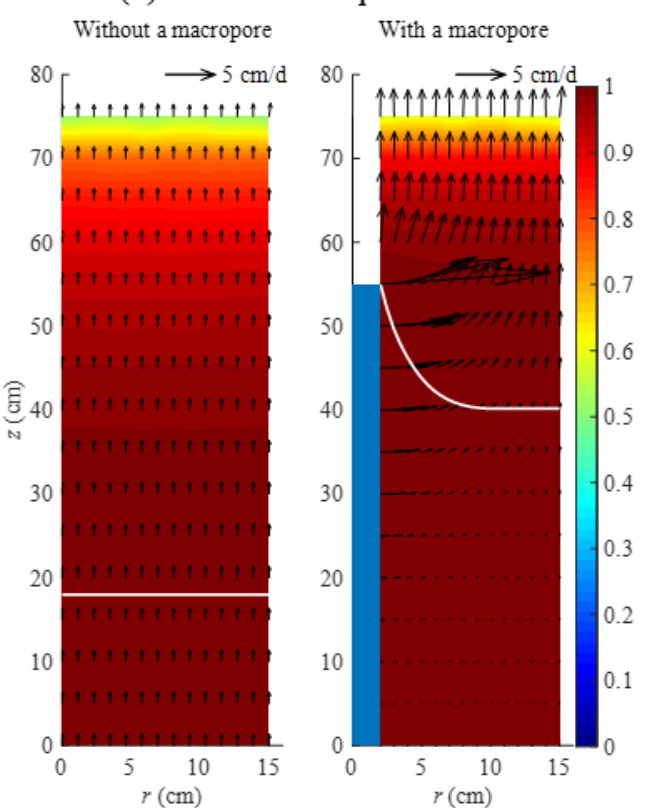

(d) Watertable depth $=60 \mathrm{~cm}$
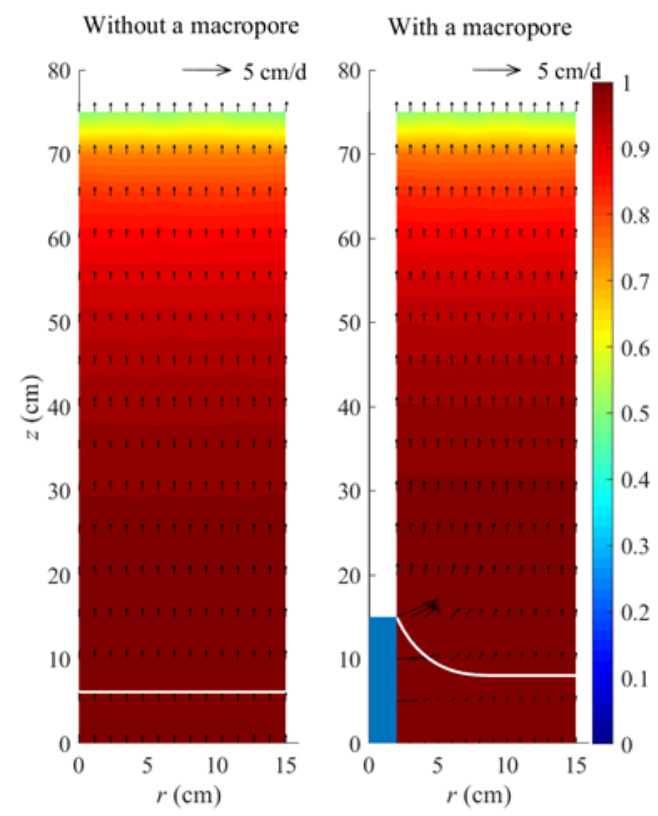

Figure 8. Simulation results for the clay experimental columns without (left) and with (right)

624 a macropore for watertable depths of (a) $0 \mathrm{~cm}$, (b) $20 \mathrm{~cm}$, (c) $40 \mathrm{~cm}$, and (d) $60 \mathrm{~cm}$. The

saturation is shown in color, while the arrows represent the Darcy velocities (the magnitude is 
628

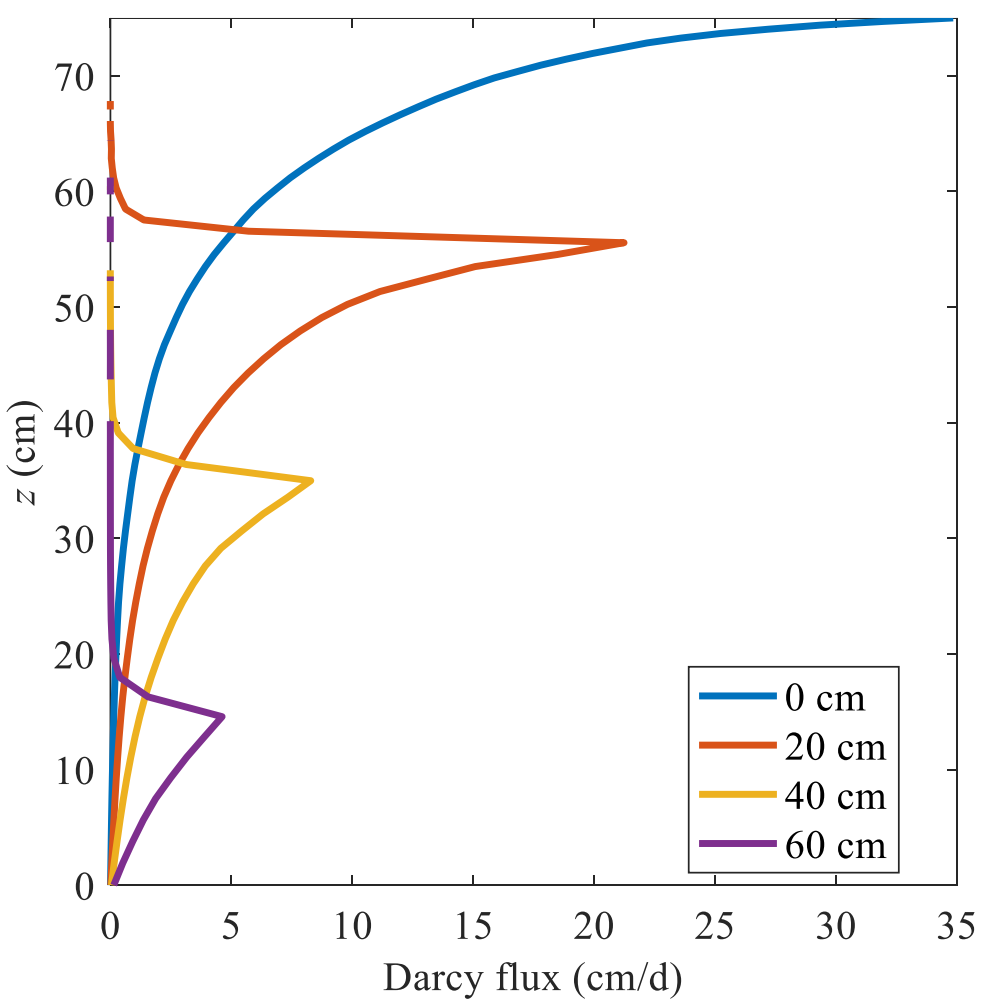

629

630 Figure 9. Simulated horizontal Darcy fluxes at the macropore boundary for the clay columns

631 with different watertable depths. 

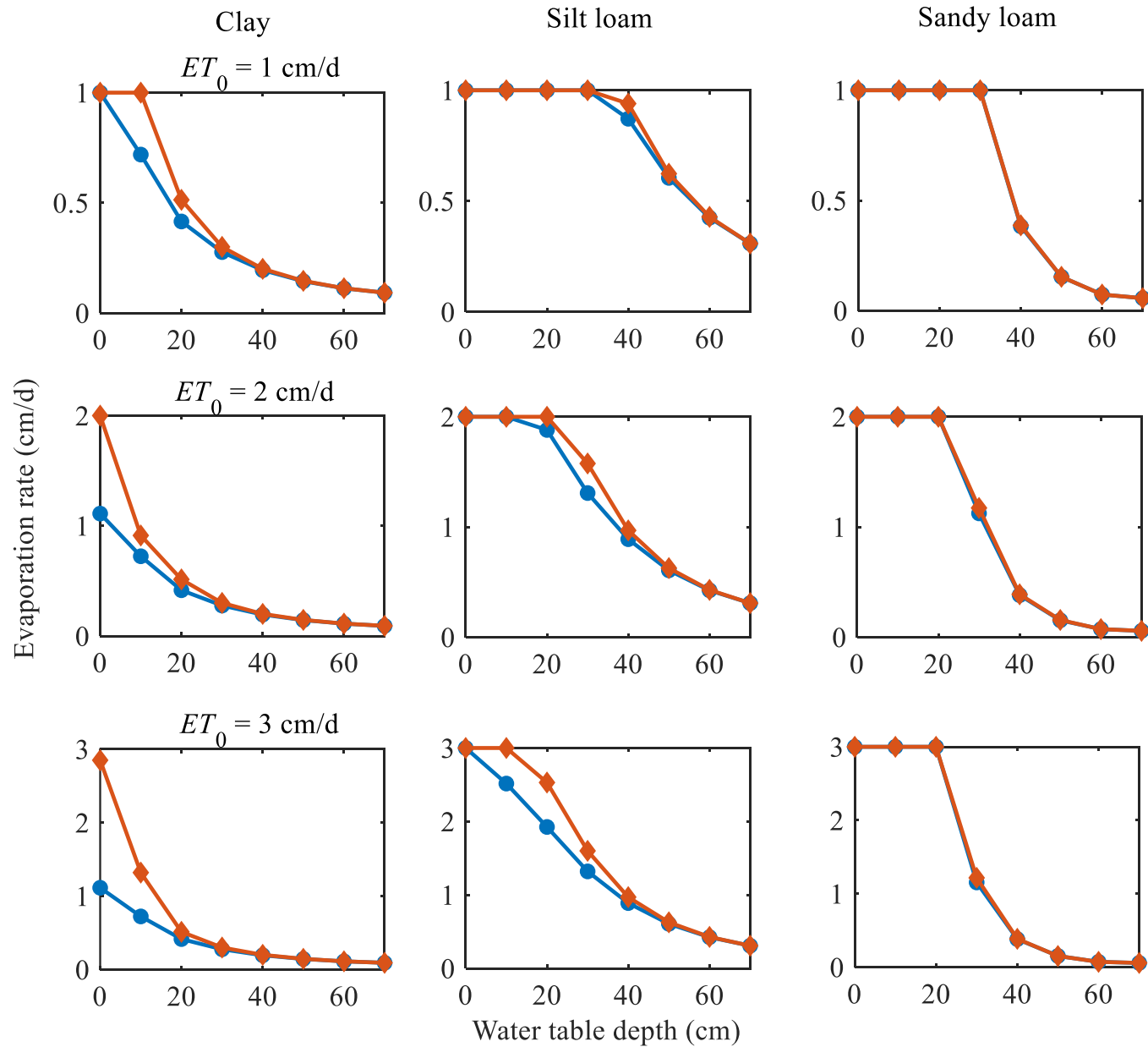

632

$\multimap$ without a macropore $\multimap$ with a macropore

633 Figure 10. The effects of potential evaporation $\left(E T_{0}\right)$ and soil type on actual evaporation for

634 soils with and without a macropore. The first, second, and third columns show the simulation

635 results for clay, silt loam, and sandy loam, respectively. The potential evaporation rates are the

636 same for each row and given in the figure titles. 


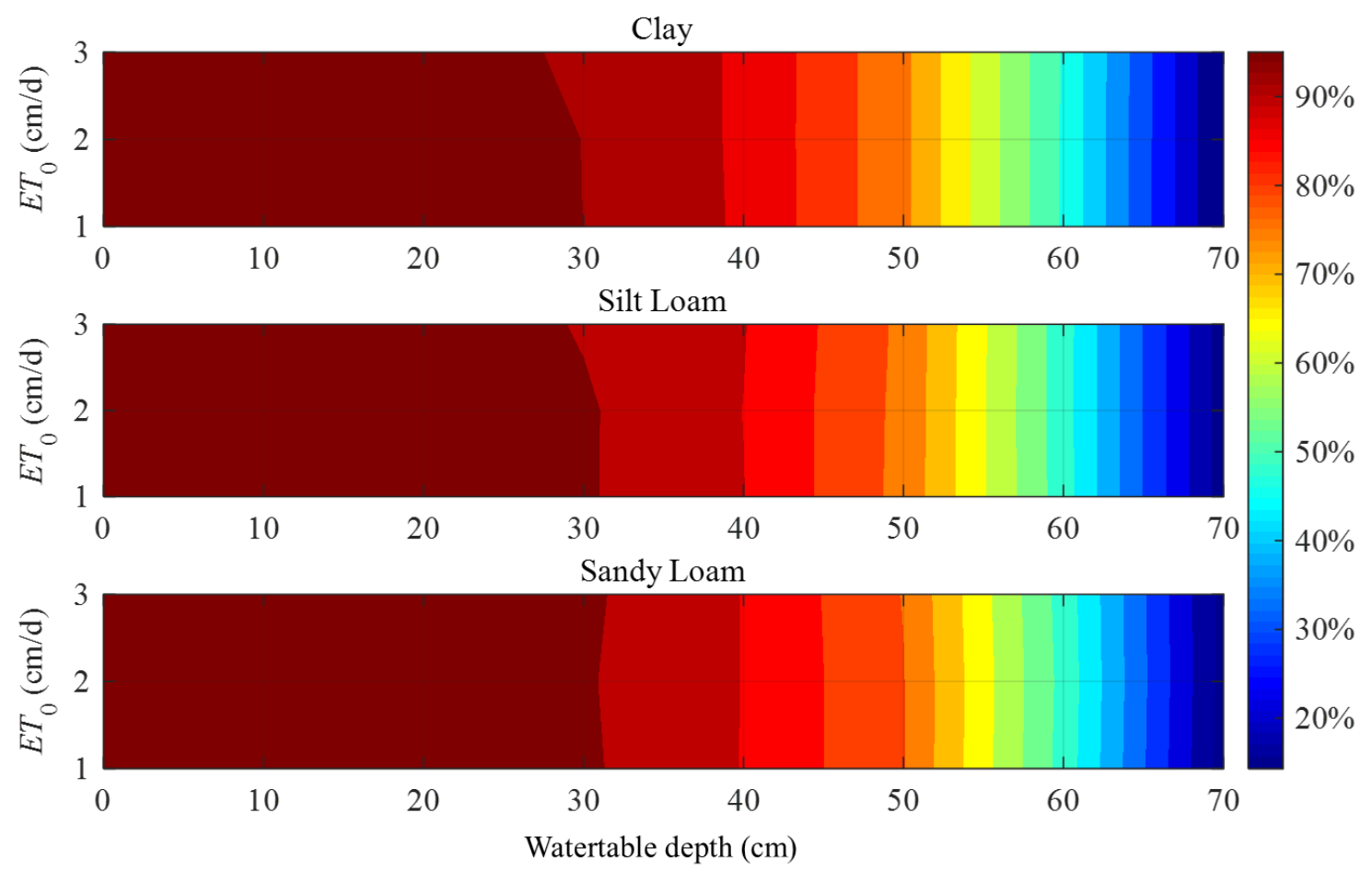

637

638 Figure 11. Ratios (in \%) of the water flux through the macropore to the actual evaporation

639 rate for different potential evaporation rates $\left(E T_{0}=1-3 \mathrm{~cm} / \mathrm{d}\right)$, groundwater levels $(0-70 \mathrm{~cm})$,

640 and soil types (clay, silt loam, and sandy loam) considered in the sensitivity analysis. 